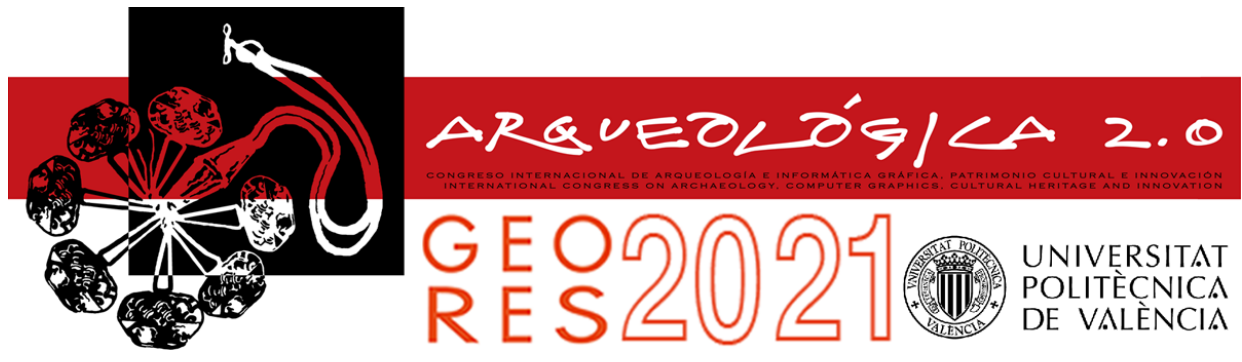

Proceedings of the joint international event $9^{\text {th }}$ ARQUEOLÓGICA

$2.0 \& 3^{\text {rd }}$ GEORES

Valencia (Spain).

26-28 April 2021

\title{
DIGITAL CULTURE, UMWELT AND ALETHEIA AN ONTOLOGICAL INTRODUCTION
}

\author{
Andrea Pasqui \\ Department of Architecture, Built environment and Construction engineering (ABC), Politecnico di Milano, Via Ponzio 31, Milano, Italy. \\ andrea.pasqui@polimi.it
}

\begin{abstract}
:
The paper presented here focuses on the idea of interpreting the digital culture as an image of the material culture rather than a mere copy of it. First of all, we should ask ourselves what an image really is; it is in investigating its deep meaning, which is often devalued due to the enormous dissemination of void images, that we can overcome the superficial concept of the digital as a digitalised copy. The description of an archaeological artifact cannot prescind from its physical and material appearance, but has to go further towards its profound nature and meaning. Considering the so-called aura of archaeological and artistic objects as an engagement between the hic et nunc of the object and the hic et nunc of the observer it will be possible to go beyond in the comprehension of the agency of the objects. Moreover, it is necessary to consider technology as a way through which objects could reveal themselves in a process of $\alpha \dot{\lambda} \eta \dot{\theta \varepsilon} \alpha$ and not just a tool with the only scope of showing itself and its capacities. Considering digital copies as images could yield compelling challenges: every archaeological object, at any scale from the very little to the very big, has its own lost Umwelt: a way of being entangled in the world in which it was created. Probably, no answer will be provided within this paper, but suggestions to move towards an ontology of digital objects and their relationship with virtual realm.
\end{abstract}

Keywords: virtual archaeology, landscape, recontextualisation, image, digital culture, material culture

\section{Expanding images}

In recent years we witnessed the spread of a sheer amount of digital material consisting most often in different types of photographs. The risk, in this case, is to become immunized to the power of images which are getting every day voider and mere exhibition of their superficial charm. As Wim Wenders (2015, p.41) stated during an interview with his Italian editor, 'La saturazione di immagini è tale che le immagini che ci circondano sono diventate irrilevanti: sono talmente tante che finiscono per diventare arbitrarie, per non rappresentare più nulla. Trasmettono solo se stesse, o un'idea completamente vuota' As the aim of this research is to go further in the comprehension of the value of digital culture as an image of the material, the first step is to give back to images their former prominence of 'cultural objectivations' (Assmann, 2010, p.109). As illustrated in the following sections, while staring at a wonderful archaeological find in a museum, we are already facing an image of the former object.

What is an image? First of all, it has to be said that an image is not a picture. At best, a picture can contain an image. Above all, an image is something that is created primarily in our mind or at least is in our mind that reaches its complete form. Greek mythology is full of examples: Euripides, for example, tells us that the entire war of Troy has been fought for a ghost and not for the true Helen, hence just for an image of Helen. This concept of image as a "double" of the reality recurs often in Homer too: in
Iliad, Achilles tries to embrace his friend Patroclus in dreamtime and is shocked when his image vanishes between his arms. Similarly in the Odyssey, Odysseus is upset when he fails embracing his mother in Hades (Valditara, 2007). Later on Plato referrers to inner imagery as something in a way more "positive": in the Theaetetus $(191, \mathrm{c}, \mathrm{d})$ he conceives memory as a wax tablet in which, through our perceptions, images are inscribed. Something similar is mentioned in Philebus $(39, b, c)$ where he speaks about a metaphorical painter who create mental images of what we physically perceive.

Briefly, an image, is the inner reproduction of what we perceive through five senses, but at the same time it could be something completely detached from physical perception and existing a priori in our mind produced by the cultural influence that society has. It has to be noted that not only the sense of sight concurs to the creation of images, but it cooperates with all others in a phenomenological scenario. As we shall see later on, cultural background is crucial in the process of imagination. It is for this reason that when we stare at an archaeological find inside a showcase, the image of that object could not be the same as the one people that made it used to have: just because our "mind" is born and raised in a completely different environment (Ingold, 1993), hence it has developed different kind of approaches to manufact or ancient buildings which we could find "beautiful" without being touched - or culturally activated - by them. 


\section{Concerning the aura}

What makes an archaeological object unique is its agency, its aura. But what exactly is the so-called aura?

We can consider it as an engagement between two different hic et nunc (Benjamin, 1935). First of all, the hic et nunc properly pertaining to the object comprehending the core elements which form its being. We can summarize them all in three categories: environment, material and shape (Fig. 1). We can assert that these elements form the thing regarding just its physical side. But creating an object does not imply just tangible elements: the human factor is crucial. Nevertheless, this should not be seen only by the side of the human interaction with primary products, the manipulation of raw materials, but we have to consider the way in which humans simultaneously create and are created by their artifacts. Self-awareness and, broadly speaking, culture, is possible only by creating the other (Assmann, 2010; Greco, 2019; Hodder, 2012). This mutual interference between subject and object could be explained under different point of view. On the one hand, as Leroi-Gourhan (1964) states, the shape of the amygdala, one on the first tools created by humans, spawned by, let's say, a crystallisation of their gesture. From this point of view the amygdala is conceived as a sort of natural prolongation of human body and gestures. On the other hand, trying to avoid an hylomorphic perspective, Tim Ingold argues that the actual shape of the tool unfolds thanks to the interaction of human gesture and the developmentpotential intrinsically pertaining to the material itself (Ingold, 2013). Despite this opposition, that could be easily overcome considering mental imagery not as rigid schemes entirely existing a priori but as fluid and dynamic interaction between perception and knowledge (Freud, 1954), what appears clear is that assimilation requires reelaboration. It is not enough to see - or to hear something - to "grasp it". A true perception requires action, and it is in this mutual engagement between the object of our perception, our pre-existing concepts and our actions that knowledge and self-awareness emerge. There is a widely known example that could clarify the essential relationship between subject and object. As MerleauPonty suggests, we are led to ask ourselves where do the self of a blind man begin: at his hand or at the end of his white stick?

As many scholars state, human mind and body do not halt at the physical end of our body, neither on our fingertips nor at the top of the head, but continue in the man-made objects (Renefrew, Frith, \& Malafouris, 2009; Greco, 2019). In the light of recent studies (Freedberg \& Gallese, 2007) we can assert that perception of a work of art or, more in general, of an object or even of the landscape, has precisely material basis in the physical conformation of human brain. What appears clear is that the way we see and experience a man-made object is influenced both by our culture and our neurological system which provokes an embodied simulation of what we are seeing based on a concept of empathy. This does not mean that cultural background plays a secondary or in a way minor role (Assmann, 2010). Quite the contrary. Culture and neurological response are reciprocal influenced.

In this regard, adherents of phenomenological archaeology argue that an embodied experience of monuments or landscape could help us understanding the way in which ancient civilisation used to perceive their world (Hodder, 2012; Tilley, 1994). As will be examined below, reconstructing ancient world is quite hardly probable, at least from the physical side: but the virtual realm could help us in creating meaningful recontextualisation and virtual reconstruction of how the world used to looks like for ancient people. Recontextualisation that won't be aimed to simulate the past, but whose purpose will rather be narrate and recount stories which should raise active and transformative engagement with the observer. In a word, recontextualisation that will become fertile image of the past.

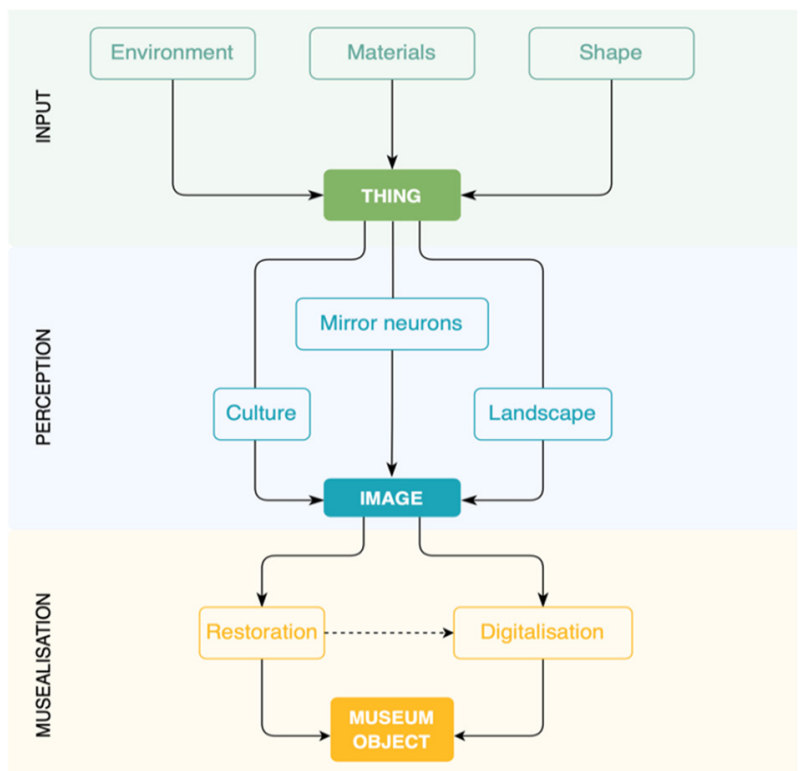

Figure 1: Diagram enhancing relationships between an object and its former components. A thing is transformed into an image through the cultural conception of it. Flowchart by the author.

In the framework of this one-to-one relationship between thing and human, we must consider three further layers which contribute to the identity of the object - hence of the subject. What transform a "inert object" into a cultural objectivation, or image, is the union of three elements: the culture that makes the object itself (Benjamin, 1935; Hodder, 1984); the landscape - which differs from the environment, mostly intended as merely natural elements (López, 1986; Casey, 1997; Brück, 2005); and the way in which humans perceive the object (Fig. 1).

Let's talk about some examples. In Museo Egizio of Turin a reconstruction of the tomb of Iti and Neferu, discovered by Schiaparelli in Geblein in 1911, is shown. The layout of wall paintings here exhibited is coherent with the former shape of the tomb itself. It could be useful to think about the former tomb keeping in mind the diagram of Figure 1. Obviously, the address of our attention is the tomb, here regarded as the "thing". Considering it from the physical side its main former element is the environment, which provides some kinds of raw materials which for their part require and suggest one or more possible shape. Being a rock-cut saff tomb (Snape, 2011), this tomb is primarily built with mudbricks provided by surrounding environment, and the stone in which is dug into. This tomb consists of 11 chambers arranged in a row facing a pillared corridor overlooking the Nile. The wall was covered with paintings. The substrate of this paintings, as 
we can see in Museo Egizio, is made out of easily findable material - clay and straw. We should now focus on one of this painting, located in the northern corner of the tomb (Fig. 2). The scene represents workers transporting grain to the silos. As western observer we could note some unusual and not so easily comprehensible element such as the fact that the bag upon mule's back is represented upside down. The cause of this lack of "communication" between us, as observer, and the painting is due to the gap that exist between our perception of the object and the way ancient Egyptian perceived it. Ancient Egyptian used to see it not only as a thing, but as an image arisen from their particular way of relating with the thing itself. As mentioned above, to transform a thing into a "cultural objectivation", is necessary the mediation of at least two elements: culture and landscape. Ancient Egyptian culture used to consider paintings and hieroglyphs as something magical. A depiction should be as clearer as possible in order to represent the subject without any kind of possible misunderstanding (Gay, 1994): the mule aforementioned is carrying two bags, and two bags should be depicted. The only way to represent them both is to draw the back one reversed upside down. The theoretical background of Egyptian iconography lies on the fact that, of a picture, exist what is evident.

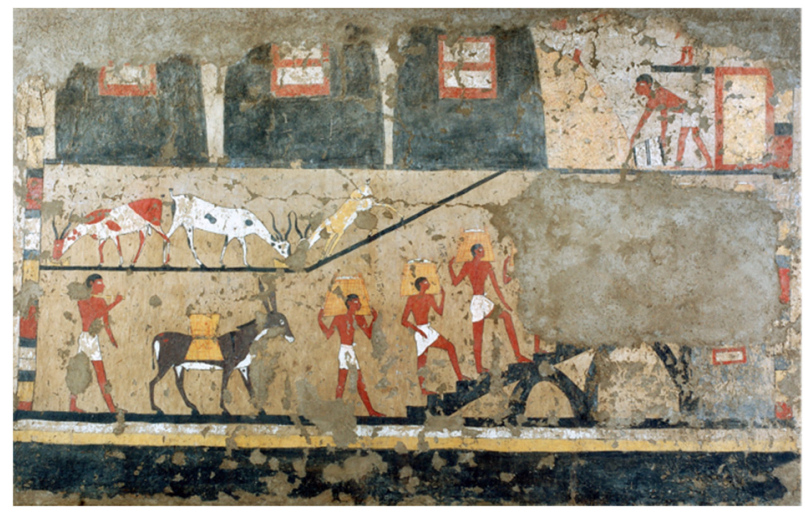

Figure 2: Wall painting from the tomb of Iti and Neferu, in Museo Egizio, Turin. Photo by Nicola Dell'Aquila and Federico Taverni/Museo Egizio.

Furthermore, another element which could help us to come closer to ancient Egyptian way of considering this tomb is "looking to" the Nile. As well shown in Museo Egizio, this tomb was facing the Nile. This feature, which for modern-era-people could be considered just as part of the environment, was otherwise conceived as crucial for ancient Egyptian. It was the source of life, Egypt itself was

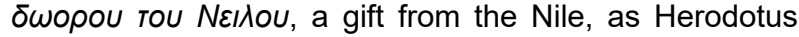
said. Recontextualise ancient manufacts or buildings means, in short, wave the manufacts together and within its loci, the latter not to be intended just as geographical environment.

Thus, the power of images is becoming clearer. While looking at an archaeological find, we are moved towards it, culturally and physically. But what has to be repeated is that we are not looking at it as the people who made it millennia ago were doing. While looking at the sarcophagus of Butehamon in Museo Egizio di Torino, we are facing a wonderful manufact dating back to Third Intermediate Period, but, no matter how specialised and accurate our knowledge may be, we could never give it the same significance and value ancient Egyptians used to. In this sense, we are already in front of another image of the home for the eternity of Egyptian. It is crucial to grasp this gap between the former object created by the ancients and the museum object we are in front of.

We could find four causes for the former object: 1) causa materialis, namely the wood used for the coffin, plaster and colours; 2) Causa formalis, which is the shape and the manner of the sarcophagus; 3) Causa finalis, meaning the purpose and the intention of the manufact to provide the scribe Butehamon his home for the eternity, and finally; 4) causa efficiens, the artisans who made it with their knowledge (Heidegger, 1954; Hui, 2016).

Now what makes the sarcophagus of Butehamon the real sarcophagus of Butehamon is the third cause or causa finalis (Heidegger 1954), hence the ritual and

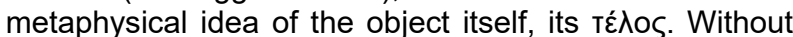
this specific causa finalis, it would be just a coffin. Grasping the gap between former object and museum object means realising that what we are standing in front of is something, let's say, constructed by the mind: in fact, it is an image.

Said this, we can underline the principle which stands at the basis of the value of archaeological finds: what makes an historical artifact noteworthy (leaving aside the concept of quality) does not lie only in its materiality, and that's quite obvious, but neither in its own and mere cultural background. The agency of an object displayed in a museum necessarily resides in that engagement produced between the hic et nunc of the object and that of the observer. We could define the hic et nunc as the peculiar way in which every subject perceives an object and at the same time gain self-awareness. This way of perceiving is influenced - and broadly speaking produced - by the society in which he lives and the landscape in which he is nested - which in a way generate the society itself (Fig. 1). The manufact displayed inside a showcase has a new life; it is not, or at least not only, the object conceived and created centuries or millennia before.

It is for this reasons that digital objects should not be considered on a lower level than physical object. It could be easier to gain self-awareness inter-acting with a virtual reconstruction than with some "scattered pieces".

\section{Virtualisation and actualisation}

Despite living in a world embedded in smart devices and computers, the "virtual" realm is still largely debated. If the aim of this work is to underline the theoretical principles for an effective involvement of digital culture in the archaeology field, it is necessary to draw up a theoretical environment in which clarify, first of all, what a digital object is, and then which are its potentials and limits. Insofar digital objects have to be taken for granted nowadays, they need an ontological framework.

Virtual and digital, although they broadly refer to the same thing, carry deep differences in their original meaning. The term "digital" refers to a notion of computing, deriving from "digit" - for its part being derived from Latin digitalis - to be considered as numerical issue. Different matter for "virtual", traceable to a question of potentially-being. No better definition of what is virtual has been given than the one by Pierre Lévy: 'The virtual is by no means the opposite of the real. On the contrary, it is a fecund and powerful mode of being that expands the process of creation, opens up future, injects a core of meaning 
beneath the platitude of immediate physical presence.' (Lévy, 1999). The first thing that needs to be underlined is that "virtual" is not something opposed to the real. This aspect is crucial while considering the relationship between material and digital culture. A digital object is not a surrogate of the "real". Digital culture is not displayed just when a display of material objects is not possible, or at least not only. Clearly, in this time of pandemic, digital culture seems to be the only way to access to museums and collections but is desirable - and likely probable - that a serious effort in order to include digital culture in museums' agendas will be done even when pandemic will be over.

As suggested by Lévy (1999) "physical absence" opens up to several chance of, let's say, creation. The term virtual should be compared to "actual" instead of "real". In such a case, the notion of virtual would undergo a deep enlargement of meaning: virtual would not be by no means something un-real, rather than a re-presentation of something possible. If some scholar legitimately criticise the term "reconstruction" referred to digital models of archaeological buildings, since a reconstruction would entail a high level of confidence regarding the original shape of the manufact (Clark, 2010), this matter should not even arise being aware of the specific meaning of the term "virtual". A virtual reconstruction is, as intrinsic in its etymology, a possible answer to some questions. It is not something "certain". Actually, the term "simulation" suggested by Clark would be more misleading, implying an idea of "imitation" or fake. A virtual reconstruction, or to avoid any conflict, a virtual recontextualisation, is far from being an imitation: it is an actualisation of one possible layout. Being buildings or object from the distant past the focus of these kind of studies, a complete level of confidence regarding their original appearance will evidently be just a chimera. Exactly for this reason, for the uncertainty embedded in the archaeological discipline, a virtual recontextualisation is a unique tool which allows scholars to ask specific questions to the manufact and deliver ad hoc representations of specific problematic situations (Lévy, 1999).

To further explain the identity of virtual, we can think about the process of actualisation, by means of which "virtual" becomes "actual". Thanks to this process, something possibly-being becomes in-being and the initial state of things undergoes a transformation. Let's take an example: the above-mentioned amygdala, as the others tool invented by humans, went through the concept of virtual in its making process. Human strength was conceived as virtual, extrapolated by the actual context, made an abstract entity. Human movements needed to de-flesh animals' skins, to chop vegetable or to work ropes were transformed into "problematic entities", virtual indeed. After that, a possible actualisation of the virtual strength was transformed into actual in the shape of the amygdala.

\section{Digital objects as images}

Defining digital objects' ontology is not immediate, just as much as putting them into a precise category. Hui (2016) legitimately put them in their own discrete category as subset of technical objects. It has to be noted that technology is something that have always characterised human species and not something directly related to digital development. In this perspective, human's life has been depending on a close relation with technology and its evolution since the stealing of fire at the hand of Prometheus.

One of the more pressing issue about digital objects is if they are worth a definition of object "in itself" or just as representation of a material objects. I will dare to propose that digital objects are worthy of the value of real object since they possess several qualities of their material counterpart. First of all, and here is the focus of this work, they are, exactly as material objects, images of the former artifacts. As we ventured to state above, a museum object ceases to be its former, becoming a new entity: an image of the original and ancient object, since no one could see it as the civilisation that conceived and created it. Obviously, this does not mean that it is not worth displaying it into a museum, quite the contrary. But it has to be clear that museum objects are something other: as stated above, an image is something that primarily arise in our mind, influenced by our way of perceiving the world.

Nevertheless, notion of digital as a copy of the material, should be considered with great attention, starting from the idea itself of copy. It is appropriate to begin this argument with a Chinese saying: 'Under normal conditions we adhere to the rules of convention, but in times of change we use quan' (Han, 2011). Quan stands for law, although representing an idea of law completely different from the absolute European one, being quan the moveable and adjusting sliding weight on a scale.

The quintessential combination of the notions of copy and that of recontextualisation consists of the case of Veronese's Nozze di Cana. The painting was conceived to merge with Palladio's architecture at Isola di San Giorgio, Venice, in order to give Benedictine Monks' refectory a tromp l'oeil effect of depth. In 1797 Napoleon send it, cut into strips, to Paris, where is still displayed in Mona Lisa's room. It can be asserted that here the painting is completely de-contextualised, displayed in a place absolutely different - in its dimension, lighting condition, height, presence of frame and son on - from the former one. For this reason, in 2006 Factum Arte started working on a 1:1 high definition "threedimensional" copy of Nozze di Cana (Fig. 3) in order to re-place it in Venice, in its original landscape.

Would it be reasonable to say that the aura of the painting has migrated from Paris, where the ancient painting is displayed, to Venice, where a "copy" has returned in its original for which it has been painted and devised? Let's say yes. As above mentioned, aura lies, in a way, in the engagement between the object and the observer. It should not be just a question of "age" of the artifact - in this case we could not consider Roman statues copies of Greek insofar they are thousands-year-old - but, in the value of cultural activator value that artifact from the past do have. We should not visit museum just because the display ancient objects. In the aforementioned example, the hic et nunc of Nozze di Cana has nothing to do with Paris and Louvre, rather than its origins are in Venice. Moving away from a certain fetish view of works of art as "untouchable reliquiae", how could an observer be touched by Nozze di Cana's aura, if he/she could neither observe its details - due to disproportioned quantity of people crowding the room (Latour \& Lowe, 2010)? 


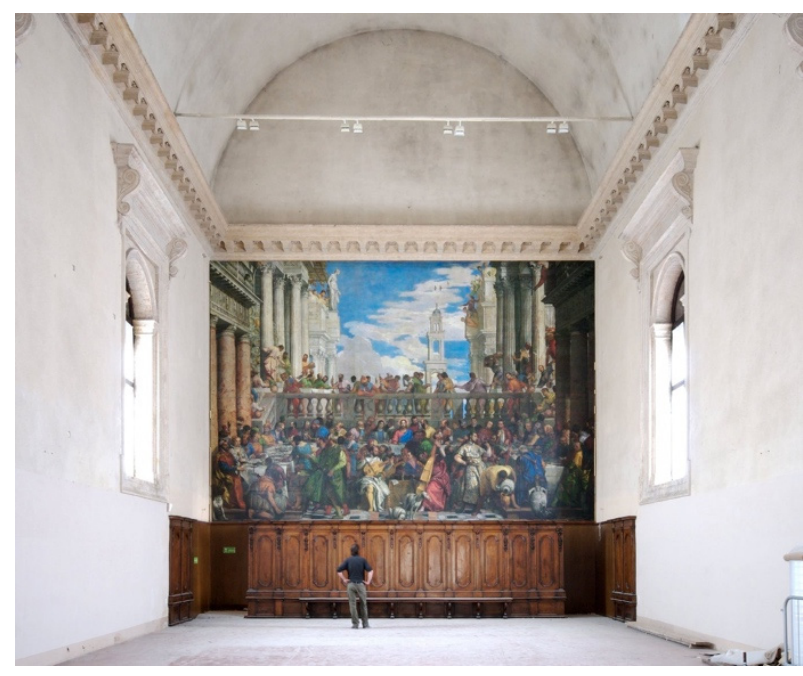

Figure 3: Nozze di Cana fac-simile in its original landscape. Source: Adrian Lowe, Factum Arte's head.

Why copies are considered so evil, nowadays - at least in Western world? Accordingly to Latour \& Lowe (2010) the focus should not be the existence of copies, rather than on their quality. The high quality of Nozze di Cana fac-simile makes it absolutely worth observing it and considering it qualitatively equal to the original. Technology, which as we will further see, has the power to act as a means of unveiling of hidden issues and features. A skilful use of it allowed Factum Arte to realise a copy of Nozze di Cana in pigment on a canvas coated with gesso, just like the one created by Veronese. A copy which actually has more of that auratic quality the original one in Louvre seems to have lost.

It could help to consider the Chinese word for original: zhen $j i$ literally means "authentic trace", giving a clear idea of the Eastern notion of originality. It tells us about a process instead of a permanent quality of Being (Han, 2011). Conceiving the entire world as something in process instead of a static essence, the work of art ceases to have a "date of birth". Considering the reality as something in perpetual change and evolution, there could not be any kind of attack to the concept of originality of an archaeological building or painting. For example, the famous Ise shrine, the well-known sanctuary in Shinto, Japan, is considered 1.300 years old, despite being reconstructed from scratch every twenty years.

Something not-so-different - despite apparently opposite - happens in the Western world. An ancient building, painting or artifact, is constantly monitored, protected and conserved by means of focused intervention. In historical building restoration, for example, great attention is paid to enhance the "signs of aging", treating its "aged aspect" as reliquiae. Something slightly different happens to moveable artifacts, which undergo a process of restoration and conservation inside museums. Let's stress that a museum object, or a musealised building, is not its former, it has become an image of itself by means of the many processes of re-production it has undergone along its life.

Insofar every museum object or archaeological site can be considered as an image of itself, in fact something like a replica, why should we consider digital objects on a lower level, treating them as mere copies?

\section{Surveying the Umwelt}

As already mentioned, every object, living being or ancient building is entangled in a thick system of relations with the natural environment and the society, hence with the landscape. Paradoxically, in order to adopt a meaningful approach to the realm of virtual, is necessary to step back to the environment. If, as affirmed above, the term "recontextualisation" is preferred to "reconstruction" since the latter entails a certain degree of confidence regarding the original shape of the building under consideration, great attention must be paid to the - as far as possible - original context. Relationships gather and create, but at the same time it is this gathering that creates objects. For example, let's consider Heidegger's jug. It 'takes what is poured into it, and then pours the liquid out. The water and wine come from a rock spring or from rain or from the grape growing in the earth. The pouring out can quench thirst for humans or be a libation to the gods. So the jug connects humans, gods, earth and sky. It is this "gathering" that makes the jug a thing.' (Hodder, 2012). From a more pragmatic point of view, let's think about commercial route in ancient Egypt. Caravans used to link cities in the Nile valley with oasis in the desert carrying supplies and raw materials connecting distant places and, in a way, giving them existence. Nowadays these connections are far wider and more obvious, while being at the same time more striking. Let's think about a smartphone, designed in the Silicon Valley, produced in China with raw materials and semifinished ones from all over the world and used by a European customer. The net of relationship entangles almost the whole world, transforming the environment of modern-days men in a virtually unlimited one. For ancient civilisation, fortunately, world was not so wide, giving scholars the chance of understanding and theoretically reconstruct it.

In order to undertake a progressive process towards an effective virtualisation of archaeology, is necessary to adopt an ecological approach to the reality, or better yet, to the actual. Ecology, deriving from Greek oíkos and \óyos, literally means the study of the "dwelling place". The term Umwelt suggest the idea of environment in which every living creature dwells. According to Uexküll, humans can have different umwelten despite living in the same environment (Agamben, 2002): this idea is crucial for understanding the centrality of Umwelt in archaeology. As much as two humans share an environment, their "personal environments", made of the whole system of relations they weave, could be not exactly the same. This fact entails the complexity of archaeological matter which has to keep together data from different subjects and fields: archaeobotany, philology, architecture, art history and so on. Moreover, a strong gap exists between the quantity and quality of data collected and disseminated, being the latter often more fragmented, making quite difficult an homogeneous and complete comprehension of the site (Forte, 2009). All these different features contribute, and are essential, to the comprehension of objects' umwelten.

The first step towards the comprehension of Umwelt is in the understanding of the centrality of the landscape: the cover of Casey's The Fate of Place (1997) - in its paperback edition - well represents the richness of what is landscape. Moving away from the idea that a map could represent a place in its essence, the illustration joins a photograph, a topographical map and an aerial photo of 
the same loci. In its symbolical meaning this illustration is striking. Furthermore, Tim Ingold states that 'The landscape itself is a reticulate maze of criss-crossing lines of ancestral travel, with the most significant localities at its nodal points. Localities identified by particular landscape features - hills, rocks, gullies, waterholes, and so on embody the ancestors' powers of creativity and movement in a congealed form.' (Ingold, 2000, p. 141). Being the landscape so deeply tied to human's life and development it should be itself intended as the Umwelt much more than a mere background or naturalistic concept of environment.

It has been stated that one of the major difficulty scholars have to face is the complexity of data collected and their subsequent dissemination. In this paper is suggested that the best way to put them in an effective relation is through digital objects and their virtual Umwelt: considering a virtual recontextualisation as a palimpsest is possible to manage data collected along different phases of the digging process, as well as data from different fields. In a unique model, for example, it would be possible to join and display - data regarding the actual condition of the artifact, the context in which it has been found and its possible former aspect along with results of the most varied biological, chemical, physical - but also artistic, philological, philosophical - exams and surveys, allowing for a true engagement between observer and object.

\section{Technology as means of aletheia}

Key role in this research is evidently played by technology. Overcoming the dichotomy between scientific and humanistic disciplines (Greco, 2019; Rossi, 2019) it is necessary to weave an interdisciplinary work which comprehend anthropology, archaeology, philosophy and architecture as well as specific expertise regarding digital field. Nowadays it would be foolish and counterproductive to ignore the potential of digital tools but at the same time great attention must be paid in order to employ technology productively, without using it as a manifesto of itself. At a time of daily achievements and new discoveries in digital field, the employment of technology does not have to be necessarily aimed to obtain the most innovative product, rather than the most useful and compelling regarding the ongoing research (Rossi, 2019).

In order to take advantage of technology enhancing its value of moínб/s, we have to consider it as a means by which revealing of hidden information and characteristics of the case study is possible and accomplished. It has to be noted, above all, that working with digital culture does not mean digitalizing collections. Digital culture does not consist of photographs on a museum website, or at least, not only (Meehan, 2020). A digital object should be intended both as a tool for surveying the material object and an image of the object itself with the power of creating active and transformative engagement with the observer (Hogsden \& Poulter 2012).

While working on the advanced survey of the coffin on Butehamon carried on by 3D Survey Group of Politecnico di Milano, (Mandelli et al., 2019), the 3D model created from sub-millimetric survey and the information obtained through non-invasive analysis, serves as a way of acting of $\alpha \dot{\lambda} \hat{\theta} \theta \varepsilon / \alpha$ (disclosure), being a tool by which investigate actually non-visible elements - such as the fact that the sarcophagus had been reused joining parts of pre- existing coffins -, and at the same time - and at different phases of the work - as an image of the former sarcophagus, as shown in the temporary exhibition Archeologia Invisibile held at Museo Egizio di Torino last year. The advanced sub-millimetric survey allowed the creation of a 1:1 3D printed model for the focal installation of Archeologia Invisibile (Fig. 4) which acted as support for re-projecting images onto the coffin's surface becoming the quintessence of an archaeological object's image: in fact, it serves for the projecting of different analysis results (Fig. 5) such as radiometric and colourimetric studies showing at the same time the object itself and its formerly undisclosed features, now disclosed thanks to the technology potential of being means of $\alpha \dot{\lambda} \eta \dot{\theta \varepsilon ı}$.

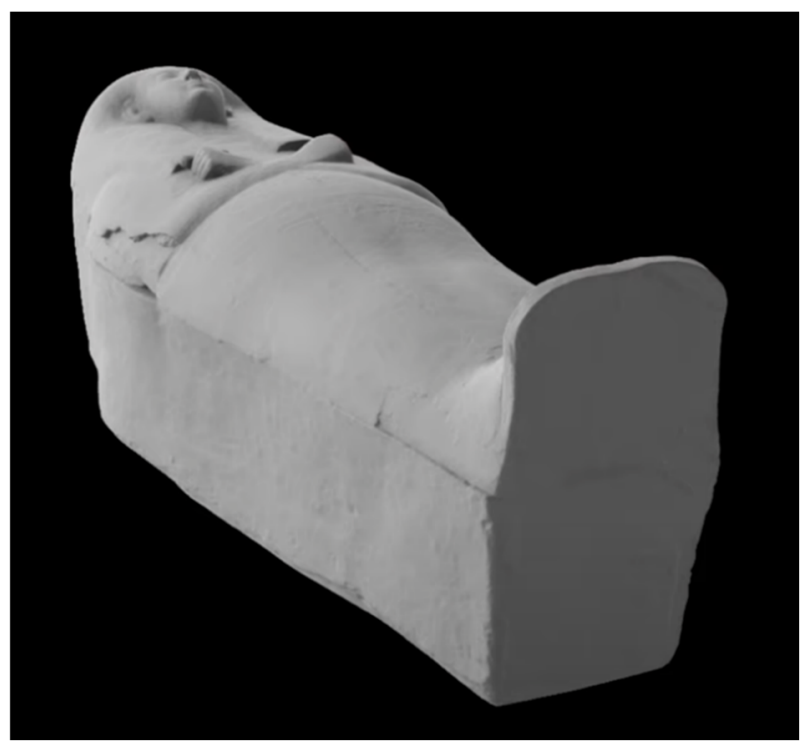

Figure 4: Video capture of Butehamon's sarcophagus 3D printed model before details projection. Source: Museo Egizio's YouTube channel.

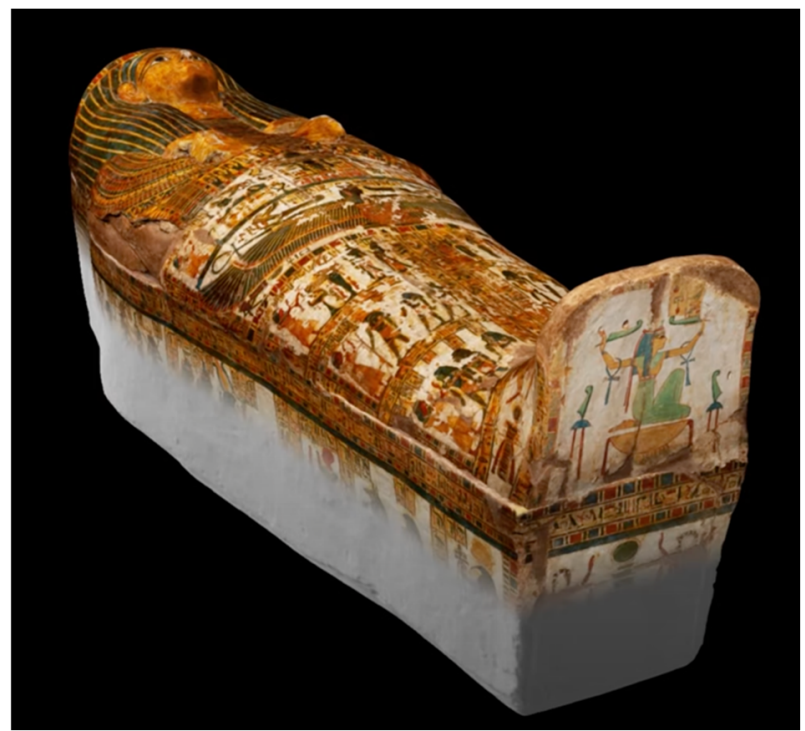

Figure 5: Video capture of Butehamon's sarcophagus 3D printed model during details projection. Source: Museo Egizio's YouTube channel.

Thanks to the features of advanced survey techniques and $3 \mathrm{D}$ modelling, scholars from different disciplines 
cooperate in order to reconstruct the Umwelt of archaeological finds suggesting a virtual recontextualization without overlooking at the new Umwelt that every object has in its new life as a museum object. All these elements contribute to the biography of the objects (Greco, 2019) and are crucial in the close dialogue that occurs between them and the observer (Meehan, 2020). For this reason, re-contextualisation is compelling and culturally challenging: successful recontextualisation would entail a deep comprehension of how the artifact looked like at the eyes of ancient people and will be possible only if carried out in a multidisciplinary environment in which dissemination and study purposes will go together.

Modern survey techniques are essential especially since they allow a - virtually - simultaneous work of data collection, elaboration and dissemination. A crucial aspect of modern archaeology is the study of the complex stratigraphy of a site which conceals features and important information that could get lost if not properly surveyed. As shown in Archeologia Invisibile, photogrammetrical surveying allows this type of elaboration since it enables surveyor to collect a large amount of data in relatively short time. Elaboration of this data, furthermore, provides a virtual landscape in which coexistence of dataset from different disciplines is possible and easily achievable.

\section{Conclusions}

In conclusion, every object has its Umwelt, its own specific cultural landscape in which it is deeply entangled. A landscape made by a substrate of geographical elements combined with a sheer number of cultural connotations. For humans, creating an object means objectifying cultural memory making it durable and crosstemporal (Assmann, 2010). An object could - and perhaps should - never be just a "thing". Studying artifacts dating back to millennia ago could entail great difficulties in investigating their lost Umwelt. Digital tools - and digital objects to be considered as medium of $\alpha \dot{\alpha} \lambda \dot{\theta \varepsilon l \alpha}$ and as images - could reveal their potentialities in working through these difficulties, creating a multidisciplinary environment aimed at a deep comprehension of the artifacts from the past and, at the same time, to find new and more efficient ways to display archaeological finds and remains and contribute to an effective dissemination of knowledge.

\section{Acknowledgements}

My gratitude goes to Prof. Corinna Rossi (Department $A B C$, Politecnico di Milano) for her extraordinary guidance and continuous support during the different phases of this work, and to Prof. Stefano Natrella (Accademia di Belle Arti di Brera) for our extremely fruitful discussions regarding, among others, the concept of image. Finally, thanks to Prof. Todd Shimoda for his brilliant support. This paper represents an outcome of the project LIFE (Living In a Fringe Environment) funded by the ERC CoGrant 681673.

\section{References}

Agamben, G. (2002). L'aperto: l'uomo e l'animale. Torino, IT: Bollati Boringhieri.

Assmann, J. (2010). Communicative and cultural memory. In A. Erll, \& A. Nünning (Eds.), Cultural memory studies: An international and interdisciplinary handbook (pp. 109-118). Berlin, Germany: Walter de Gruyter.

Benjamin, W. (1935). Das Kunstwerk im Zeitalter seiner technischen Reproduzierbarkeit. Frankfurt/Main, DE:Suhrkamp.

Brück, J. (2005). Experiencing the past? The development of a phenomenological archaeology in British prehistory. Archaeological Dialogues 12(1),45-72. https://doi.org/10.1017/S1380203805001583

Casey, E. S. (1997). The fate of place. Berkeley, USA: University of California Press.

Clark, J. T. (2010). The fallacy of reconstruction. In M. Forte (ed), Cyber-Archaeology (pp. 63-73). Oxford, UK: Archaeopress.

Forte, M., (2009). Cyber-Archaeology: Notes on the simulation of the past. Virtual Archaeology Review, 2(4), 7-18. https://doi.org/10.4995/var.2011.4543

Freedberg, D., \& Gallese, V. (2007). Motion, emotion and empathy in esthetic experience. Trends in Cognitive Sciences, 11(5), 197-203. https://doi.org/10.1016/j.tics.2007.02.003

Freud, S. (1954). The origins of Psychoanalysis: Letters to Wilhelm Fliess. New York, USA: Basic.

Gay, R. (1994). Proportion and Style in Ancient Egypt. London, UK: Thames \& Hudson.

Greco, C. (2019). Keynote: The biography of objects. Int. Arch. Photogramm. Remote Sens. Spatial Inf. Sci., XLII-2/W11, 5-10, https://doi.org/10.5194/isprs-archives-XLII-2-W11-5-2019

Heidegger, M. (1954). Die Frage nach der technik; Wissenschaft un Besinnung. In M. Heidegger, Vorträge und Aufsätze. Pfullingen, DE: Günther Neske.

Hodder, I. (1984). Archaeology in 1984. Antiquity, 58(222),25-32. https://doi.org/10.1017/S0003598X00055940

Hodder, I. (2012). Entangled. An archaeology of the relationships between humans and things. Oxford, UK: John Wiley and Sons, Inc.

Hogsden, C., \& Poulter, E. K. (2012). The real other? Museum objects in digital contact networks. Journal of Material 
Culture, 17(3), 265-286. https://doi.org/10.1177/1359183512453809

Han, B. (2011). Shanzhai: Dekonstruktion auf Chinesisch. Berlin, DE: Merve Verlag.

Hui, Y. (2016). On the existence of digital objects. Minneapolis, MN: University Of Minnesota Press.

Ingold, T. (1993). The Temporality of the Landscape. World Archaeology, 25(2),152-174.

Ingold, T. (2000). The perception of the Environment. Essays in livelihood, dwelling and skill. London, UK: Routledge.

Ingold, T. (2013). Making: Anthropology, Archaeology, Art and Architecture. London, UK: Routledge.

Latour, B., \& Lowe, A. (2010). The migration of the aura or how to explore the original through its fac similes. Switching Codes, 108, 275-297.

Leroi-Gourhan, A. (1964). Il gesto e la parola. Tr. It. 1977. Torino, IT: Einaudi.

Lévy, P. (1999). Becoming virtual: reality in the Digital Age. New York, USA: Plenum Trade.

López, B. (1986). Arctic Dreams. Imagination and desire in a northern landscape. New York, USA: Simon \& Schuster.

Mandelli, A., Perfetti, L., Fiorillo, F., Fassi, F., Rossi, C., \& Greco, C. (2019). The Digitalization of ancient Egyptian coffins: a discussion over different techniques for recording fine details. Int. Arch. Photogramm. Remote Sens. Spatial Inf. Sci., XLII-2/W15,743-750. https://doi.org/10.5194/isprs-archives-XLII-2-W15-743-2019

Meehan, N. (2020). Digital Museum Objects and Memory: Postdigital Materiality, Aura and Value. Curator: The Museum Journal. https://doi.org/10.1111/cura.12361

Renefrew, C., Frith, C., \& Malafouris, L. (2009). The sapient mind. Archaeology meets neuroscience. Oxford, UK: Oxford University Press.

Rossi, C. (2019). Aristotle's Mirror: combining digital and material culture. Int. Arch. Photogramm. Remote Sens. Spatial Inf. Sci., XLII-2/W11, 1025-1029, https://doi.org/10.5194/isprs-archives-XLII-2-W11-1025-2019

Snape, S. (2011). Ancient Egyptian Tombs. Chichester, UK: Wiley Blackwell.

Tilley, C. (1994). A Phenomenology of Landscape: Places, Paths and Monuments. London, UK: Berg.

Valditara, L. M. (2007). Platone e le 'ragioni' dell'immagine. Percorsi filosofici e deviazioni tra metafore e miti. Milano, IT: Vita e Pensiero.

Wenders, W. (2015). Una volta. Roma, IT: Contrasto. 